\title{
A Teoria Antropológica do Didático como ferramenta metodológica para análise de livros didáticos
}

\author{
The Anthropological Theory of the Didactic as a methodological tool \\ for analysing textbooks
}

Marilena Bittar

\section{Resumo}

O livro didático utilizado por um professor pode fornecer uma boa aproximação com a sua prática em sala de aula, especialmente no que diz respeito ao conteúdo apresentado e às metodologias utilizadas. Pesquisas nacionais e internacionais têm sido realizadas sobre essa temática, com referenciais teóricos e metodológicos diversos. O objetivo deste artigo é apresentar a teoria antropológica do didático como uma possibilidade para realizar investigações sobre análise de livros didáticos. Com o apoio de uma revisão sistemática de pesquisas que orientei, apresento um desenho metodológico que permite modelar a atividade matemática presente em um livro didático e que leva em consideração variáveis fundamentais para tal estudo, como a instituição e o indivíduo.

Palavras-chave: Tarefa; Técnica; Organização didática; Organização matemática

\begin{abstract}
The textbook used by teachers can provide a good approximation to their classroom practice, especially concerning to the content presented and the methodologies used. Several national and international researches have been carried out on this subject, with different theoretical and methodological approaches. The specific aim of this article is to present the anthropological theory of the didactic as a possibility to research text books. Supporting by researches I have been supervised, I present here a methodological draw that allows us to model mathematical activities present in textbooks considering different aspects such as institution and individuals.
\end{abstract}

Keywords: Task; Technique; Didactic organization; Mathematical organization

\section{Por que analisar livros didáticos?}

Antes de começar a refletir sobre como analisar um livro didático (LD) é importante explicitar algumas razões de se realizar tal investigação. Para que analisar esse material? Qual o interesse dos resultados obtidos? O que um livro didático pode nos contar e o que podemos perguntar ao livro didático? Para dar elementos de respostas a estas questões trago relatos de experiências de pesquisas vividas desde meu doutorado (Bittar, 1998), quando realizei a primeira incursão nesse campo, até pesquisas que

\footnotetext{
1 Doutora pela universidade Joseph Fourier/Grenoble/França, professora da Universidade Federal de Mato Grosso do Sul, Brasil. Email: marilenabittar@gmail.com
} 
orientei e que me levaram ao uso da teoria antropológica do didático (TAD), desenvolvida por Chevallard e colaboradores.

A primeira vez que abri livros didáticos com a intenção de compreender $o$ que e como determinado conteúdo era apresentado foi durante a realização do meu doutorado, porém esse não era o foco da minha pesquisa. Um de seus objetivos era estudar dificuldades de alunos no uso da ferramenta vetorial para resolver problemas de geometria e para esse estudo o principal aporte teórico foi a teoria dos campos conceituais (Vergnaud, 1990). Essa teoria foi crucial especialmente para identificar e analisar possíveis teoremas-em-ação ${ }^{2}$, corretos ou não ${ }^{3}$, mobilizados por alunos do $2^{\circ}$ ano do ensino secundário francês ${ }^{4}$. Para isso é preciso analisar a ação do aluno diante de situações a serem resolvidas, o que implica em propor-lhes problemas, porém não quaisquer problemas. Foi então que olhar para documentos oficiais e para o livro didático, buscando compreender o ensino proposto e suas (possíveis) consequências para a aprendizagem, tornou-se incontornável. Não era possível partir para o trabalho com alunos sem um estudo a priori ${ }^{5}$ que orientasse o que fazer. Naquele momento a TAD não fazia parte das minhas escolhas teóricas e metodológicas e, além disso, as ferramentas que atualmente uso para a análise de livros didáticos estavam germinando. Então, abri cada livro a ser analisado, identificando definições e propriedades vetoriais apresentadas, buscando verificar se eram ou não utilizadas para resolver as atividades propostas. Foi um trabalho exaustivo e fino, que permitiu, por exemplo, levantar a hipótese de que os alunos seriam suscetíveis de construir o seguinte teorema-em-ação (falso): "As coordenadas de um vetor dependem de sua posição no espaço, assim se seu representante está no primeiro quadrante suas coordenadas serão positivas, no terceiro quadrante suas coordenadas serão negativas e assim por diante". A análise dos livros didáticos usualmente utilizados no ensino secundário francês foi fundamental para identificar e compreender dificuldades que o ensino ali praticado poderia gerar. Assim, as situações propostas aos alunos foram elaboradas com apoio nesse estudo.

Desta experiência, ficou a certeza de que se queremos compreender algumas das razões de dificuldades de aprendizagem enfrentadas por alunos, o livro didático utilizado por eles é uma das fontes a serem consultadas ${ }^{6}$. Não é a única, porém, como o LD é o principal material utilizado pelo professor no preparo de suas aulas ${ }^{7}$, seu estudo

\footnotetext{
${ }^{2}$ Um teorema-em-ação é uma proposição considerada verdadeira pelo sujeito que a mobiliza.

${ }^{3}$ Um teorema-em-ação é dito incorreto quando é utilizado fora do seu domínio de validade.

${ }^{4}$ Corresponde aos 5 últimos anos da educação básica no Brasil ( $8^{\circ}$ e $9^{\circ}$ anos do ensino fundamental e ensino médio)

5 Tal estudo também foi apoiado em pesquisas relacionadas ao tema, entretanto não são trazidas aqui por este não ser o foco deste texto.

${ }^{6}$ Nesse caso o tipo de análise do livro didático dependerá do objetivo da investigação.

${ }^{7}$ Pode-se considerar que o livro didático é uma instituição de referência para o professor, instituição no sentido da teoria antropológica do didático, conforme será discutido mais adiante.
} 
permite, entre outros, certa aproximação com o que é ensinado pelo professor. Consequentemente, é importante conhecer as propostas dos LD, especialmente para ajudar na elaboração de intervenções didáticas com alunos, pois, independente da escolha teórica, é preciso levar em consideração seu contexto de ensino. Porém, como já dito, a análise de LD pode trazer muitas outras contribuições para as pesquisas em didática. Nessa perspectiva, Chaachoua e Comiti (2010) evidenciam o aporte da análise de livros didáticos para apreender (e compreender) relações institucionais de um objeto em uma determinada organização matemática. Esses autores discutem a análise de livros didáticos à luz da TAD, propondo alguns elementos para a caracterização desse material: o momento de edição (publicação); a representatividade da obra; a estrutura do livro; análise ecológica; e, por fim, a análise praxeológica. Acompanho esses autores nessa escolha para a análise, conforme o leitor poderá perceber ao longo desse artigo, cujo objetivo é discutir possibilidades e contribuições da TAD para a análise de livros didáticos, por meio de uma revisão sistemática de pesquisas que orientei e que culminou com a proposição de um modelo para tal análise.

Uma análise de LD descortina ao pesquisador diversas paisagens que podem ir desde o estudo da cultura escolar em uma dada época à identificação de possíveis razões de dificuldades de aprendizagem e à elaboração de sequências didáticas. Conforme o objetivo da investigação, uma ferramenta teórica pode se mostrar mais pertinente do que outra. Não tenho a pretensão de afirmar que a TAD é a única ferramenta que permite analisar LD; a metodologia a ser utilizada deve ser coerente com as outras escolhas teóricas e com o objetivo da pesquisa. Nesse texto trago uma perspectiva metodológica que tenho usado e que tem se mostrado cada vez mais pertinente aos propósitos das pesquisas que realizo e oriento. É o que pretendo compartilhar com o leitor e, para isso, escolhi apresentar essa discussão usando exemplos extraídos de pesquisas que orientei e que realizaram análise de LD. Antes, porém, trago alguns princípios fundamentais para uma compreensão geral das ideias fundantes da TAD.

\section{Teoria Antropológica do Didático}

Para Chevallard todo saber é saber de uma instituição ${ }^{8}$, assim, o saber não existe no vácuo, isolado. Além disso, este saber sofre transformações adaptativas conforme a instituição em que vive. Este processo de transformações é denominado transposição didática (Chevallard, 1991). Cada instituição tem um conjunto de condições e restrições que devem ser respeitadas para que um certo saber possa existir nesta instituição. Vamos tomar como exemplo o conceito de área, presente em todos os níveis da escolaridade básica e em muitos cursos universitários de exatas. No $4^{\circ}$ ano do ensino

\footnotetext{
${ }^{8}$ Uma instituição I é um dispositivo social que impõe às pessoas que ocupam uma posição em I, modos de fazer e de pensar próprios (Chevallard, 1992). Assim, o livro didático pode ser considerado uma instituição para alunos e professores que o utilizam (a depender do objetivo da pesquisa realizada).
} 
fundamental, por exemplo, o cálculo de área de figuras planas é explorado por meio da ideia de pavimentação. Essa ideia aparece, implicitamente, no estudo da multiplicação, no $1^{\circ}$ ou $2^{\circ}$ ano. Nos anos finais do ensino fundamental esse mesmo conceito é estudado de modo um pouco mais formal com a apresentação de fórmulas para o cálculo da área de polígonos que podem ser justificadas, quase sempre, com congruência de triângulos. Se nos anos iniciais a ideia de área é explorada de forma intuitiva, nos anos finais começa a ter espaço uma ideia mais formal do objeto matemático área de figuras planas e, em um curso de cálculo diferencial e integral, o conceito é expandido ao cálculo de figuras planas quaisquer com a apresentação da integral de Riemann. Em cada uma dessas instituições é necessário realizar adaptações para que a ideia de área possa existir; tais adaptações são consequência das condições e restrições impostas pela própria instituição. Além disso, é preciso considerar o desenvolvimento cognitivo dos alunos e os conhecimentos já trabalhados. Estes processos aqui discutidos muito rapidamente, fazem parte da transposição didática (estudo das transformações que um saber sofre a fim de ser ensinado), e da ecologia dos saberes (estudo das condições de existência de um saber em uma determinada instituição). Ao lado disso, há, ainda, o estudo de práticas institucionais que existem em uma determinada instituição. Todos estes estudos compõem a TAD, desenvolvida por Chevallard e colaboradores. Nesse texto o interesse é focado no estudo das praxeologias propostas em livros didáticos, por isso me detenho um pouco apenas nesse aspecto da teoria.

Para Chevallard toda atividade humana pode ser descrita por meio de uma tarefa. Passar uma saia, por exemplo, é uma tarefa; passar uma calça é outra tarefa que tem semelhanças com a anterior. Podemos, então, falar em tarefas que são de um mesmo tipo: Passar roupa. Cada tarefa desse conjunto demanda uma técnica que depende do tecido de que a roupa é feita e da roupa em si: passar uma saia de pregas é definitivamente diferente de passar uma calça jeans que pode ser semelhante a passar uma bermuda jeans! O tipo de tarefa é definido (descrito) por um verbo de ação (passar) e um complemento (roupa); percebe-se assim a necessidade do complemento para que o tipo de tarefas esteja bem definido. As técnicas mobilizadas para resolver tarefas desse tipo podem ser justificadas - nem sempre explicitamente pelas pessoas que as mobilizam - por leis físicas.

Esse exemplo ilustra o modelo praxeológico proposto para descrever qualquer atividade, matemática ou não. Ele é composto por: tipo de tarefas T; técnicas que resolvem as tarefas desse tipo; tecnologia $(\theta)$ que justificam a técnicas e garantem sua validade, e, finamente, a teoria $(\Theta)$ que justifica a tecnologia. Esse quarteto praxeológico é denotado $[\mathrm{T}, \tau, \theta, \Theta]$. O bloco $[\mathrm{T}, \tau]$ é denominado de prático-técnico, ou bloco do saber-fazer; e o bloco $[\theta, \Theta]$ é denominado bloco tecnológico-teórico ou bloco do saber.

No caso particular da atividade matemática dois elementos teóricos fundamentais entram em cena: objetos ostensivos e objetos não-ostensivos. 
Nós falaremos de objeto ostensivo [...] para nos referirmos a todo objeto tendo uma natureza sensível, uma certa materialidade, e que, por isso, adquire para o ser humano uma realidade perceptível. Esse é o caso de um objeto material qualquer e, notadamente, e de objetos materiais particulares que são os sons [...], os grafismos [...] e os gestos. Os objetos não ostensivos são então todos os "objetos" que, como as ideias, as intuições ou os conceitos, existem institucionalmente - no sentido em que lhe atribuímos uma existência - sem, entretanto, poderem ser vistos, ditos, escutados, percebidos ou mostrados por si mesmos: eles só podem ser evocados ou invocados pela manipulação adequada de certos objetos ostensivos associados (uma palavra, uma frase, um grafismo, uma escrita, um gesto ou um longo discurso). (Bosch e Chevallard, 1999, p.10)

Dessa forma o estudo de ostensivos e não-ostensivos é essencial para a compreensão da atividade matemática.

Ao descrever uma atividade matemática por meio do modelo teórico proposto pela TAD, não somente os aspectos matemáticos são considerados. Para exemplificar vamos considerar uma aula dada por um professor sobre o teorema de Pitágoras no $8^{\circ}$ ano do ensino fundamental. Ele precisará decidir que propriedades e definições irá apresentar e também como irá apresentar: serão propostas atividades ${ }^{9}$ para que os alunos consigam conjecturar o teorema que depois será enunciado formalmente ou irá optar por uma abordagem mais clássica de apresentação de definições e resultados a serem aplicados pelos alunos? Em outras palavras, ao preparar uma aula o professor realiza escolhas matemáticas e didáticas. A atividade do professor também pode ser modelada por meio do quarteto praxeológico: sua tarefa é "Ensinar o teorema de Pitágoras". Para resolver essa tarefa didática é preciso fazer escolhas didáticas como as enunciadas acima. Tem-se, assim, a praxeologia didática ou organização didática (OD). O estudo dessa praxeologia é fundamental nas análises de livros didáticos, haja vista que uma organização didática está diretamente relacionada aos paradigmas de aprendizagem do "sujeito autor" da praxeologia. Gascón (2003) discute possíveis formas de OD, partindo de três modelos: teoricista, tecnicista e modernista.

Os modelos docentes teoricistas e tecnicistas compartilham uma concepção psicologista ingênua do processo didático que tem no behaviorismo sua mais clara referência. Em ambos os casos se concebe o processo de ensino como um processo mecânico e trivial totalmente controlável pelo professor: o teoricismo tende a conceber o aluno como uma "caixa vazia" que deve ser preenchida ao longo de um processo gradual que parte dos conceitos logicamente mais simples até chegar, passo a passo, aos sistemas conceituais mais complexos; o tecnicismo, por sua vez, considera o aluno como um "autômato" que melhora o domínio das técnicas mediante a simples repetição. Por todas essas razões denominaremos "clássicos" ambos modelos docentes em oposição aos "modernistas" [...] que identificam "ensinar" e "aprender Matemática" como

\footnotetext{
${ }^{9} \mathrm{Na}$ perspectiva que adotamos, atividade não é apenas o exercício de matemática, mas toda a situação na qual o aluno está inserido. Assim, ao propor algo para o aluno realizar estamos tentando colocá-lo em situação. Mesmo quando se trata de um exercício do livro didático, a atividade não é automática para o aluno e não consiste apenas do enunciado. É essa a perspectiva adotada neste artigo.
} 
ensinar e aprender uma atividade exploratória, livre e criativa, de problemas não triviais. (Gascón, 2003, p. 136, tradução nossa)

Esse modelo nos permite refletir sobre as consequências e características do ensino, a depender das escolhas didáticas.

Temos, assim, a praxeologia matemática (ou organização matemática - OM) e a praxeologia didática que permitem descrever, respectivamente, escolhas matemáticas e didáticas em uma determinada instituição. É importante salientar que a identificação, em duas instituições distintas, de uma mesma OM, porém com duas OD diferentes, indica que o processo de aprendizagem relativo a essa praxeologia matemática não será o mesmo, como buscarei mostrar mais adiante com a pesquisa de Nogueira (2008).

\section{A produção de dados à luz da TAD}

Tenho feito a opção de falar em produção de dados e não coleta de dados, pois o que o pesquisador faz não é um ato passivo de colher dados prontos que deverão, em seguida, ser analisados ${ }^{10}$. As praxeologias são modelos construídos pelo pesquisador. Vamos modelar as organizações matemática e didática presentes na obra, o que permitirá analisar a proposta apresentada, fazer inferências acerca das escolhas dos autores e sobre possíveis dificuldades dos estudantes.

Muito bem, dito isso, como fazemos tal análise? Como meus orientandos e eu produzimos os dados? Nesse artigo faço uma discussão sobre a TAD e suas contribuições para a análise de LD e apresento um caminho metodológico que elaborei com o apoio de uma revisão sistemática de algumas pesquisas realizadas e/ou orientadas por mim, composto das seguintes fases: a escolha do material (livro) a ser analisado; a separação entre Curso e Atividades Propostas (divisão do material para análise); elaboração/identificação do quarteto praxeológico matemático; elaboração/identificação do quarteto praxeológico didático; análise das organizações modeladas. É importante ressaltar que as $3^{\mathrm{a}}$ e $4^{\mathrm{a}}$ fases não precisam ser realizadas (e nem apresentadas) separadamente. E mais, o processo de análise é dinâmico, com diversas idas e vindas entre o material de estudo, o apoio teórico e os objetivos da pesquisa.

\section{A escolha dos livros a serem analisados}

Como em qualquer pesquisa a escolha do material que constituirá as fontes primárias deve ser feita em consonância com o objetivo da pesquisa. O mesmo ocorre com pesquisas como as discutidas nesse texto. A análise de livros didáticos (LD) não é objetivo principal de investigação; essa análise é feita para responder à questão central

10 Em trabalhos mais antigos realizados por mim e em parceria com meus orientandos, era usado o termo Coleta de dados, entretanto, o que era feito é exatamente o descrito nesse parágrafo: os dados não estavam nos livros prontos para serem colhidos: eram uma produção do pesquisador. Assim, reconhecendo a força das palavras optei por realizar essa mudança para que as palavras correspondam melhor ao que é feito. 
da pesquisa. Consequentemente, a escolha dos livros vai depender do que queremos investigar. Nessa seção discuto algumas possibilidades a partir de exemplos.

A primeira pesquisa que orientei com o uso da TAD para a análise de LD foi a de Nogueira (2008), cujo objetivo era caracterizar o ensino de álgebra proposto em livros didáticos destinados ao sétimo ano do ensino fundamental, quando tem início o estudo da álgebra ${ }^{11}$. A autora escolheu trabalhar com três volumes de coleções distintas, todas aprovadas no Plano Nacional do Livro Didático de 2008 - PNLD/2008 ${ }^{12}$ por fazerem parte de coleções possíveis de serem adquiridas por escolas públicas.

Nossa seleção visou contemplar manuais que tomem posturas diferenciadas no contexto educacional, seja ela tecnicista, construtivista, ou outra, desde que fosse diferente das demais escolhidas, com o intuito de obter uma maior abrangência de material para ter melhores elementos de resposta às nossas questões (Nogueira, 2008, p.48)

Com essa escolha haveria possibilidade de identificar diferentes praxeologias matemáticas, mas, principalmente, diferentes praxeologias didáticas, o que permitiria melhor caracterização da introdução da álgebra no $7^{\circ}$ ano do ensino fundamental.

Com objetivo semelhante ao de Nogueira, Kaspary (2014) investigou como o campo aditivo (composto das operações de adição e subtração) era apresentado nos anos iniciais do ensino fundamental: que conceitos, algoritmos e procedimentos estão presentes nesse nível da escolaridade e como são apresentados. Tal objeto de estudo é significativamente presente do $1^{\circ}$ ao $5^{\circ}$ ano de forma bastante acentuada. Considerando a extensão do tema e o prazo máximo de 2 anos para realizar a pesquisa foi necessário optar por uma coleção de livros didáticos. A escolha recaiu sobre a coleção mais vendida nos anos iniciais, por ser a mais presente nas escolas públicas. Por essas mesmas razões essa foi a coleção escolhida para ser analisada por Almeida (2015, p.6), que desenvolveu uma pesquisa cujo objetivo foi "investigar a abordagem do ensino de polígonos e figuras espaciais formadas por polígonos proposta em uma coleção de livros didáticos dos anos iniciais do ensino fundamental aprovada no PNLD de 2013".

A pesquisa de Oliveira (2010, p. 5) não tinha como foco a análise de livros didáticos; seu objetivo era investigar "a relação existente entre os conhecimentos adquiridos na formação inicial e aqueles mobilizados durante a prática pedagógica por um professor de Matemática em início de carreira." Para estudar conhecimentos do

\footnotetext{
${ }^{11}$ Estamos considerando o início formal da álgebra, pois antes disso há o que alguns autores chamam de pré-álgebra, o que não foi foco da pesquisa de Nogueira.

12 “O Programa Nacional do Livro Didático (PNLD) tem como principal objetivo subsidiar o trabalho pedagógico dos professores por meio da distribuição de coleções de livros didáticos aos alunos da educação básica. O programa é executado em ciclos trienais alternados. Assim, a cada ano o MEC adquire e distribui livros para todos os alunos de um segmento, que pode ser: anos iniciais do ensino fundamental, anos finais do ensino fundamental ou ensino médio". Retirado de http://portal.mec.gov.br/pnld/apresentacao em 28/03/207.
} 
professor, o apoio teórico foi a teoria da base de conhecimentos necessários para a docência, desenvolvida por Shulman (1986, 2001), especialmente os conhecimentos de conteúdo, pedagógico e curricular do objeto de estudo. Uma das fontes de dados utilizada para o estudo de Oliveira foi o livro didático adotado pelo professor que participou de sua pesquisa. A autora modelou as organizações matemática e didática presentes no LD que serviram para identificar mudanças que o professor fazia em sua aula, relativamente ao material adotado. Assim, esse é um exemplo de pesquisa cujo elemento principal não é a análise de LD; esta é feita para ajudar a compreender a prática do professor e a escolha do LD está relacionada a esse objetivo.

Visando "Caracterizar a contextualização da álgebra em LD destinados ao $7^{\circ}$ ano do ensino fundamental", Souza (2014) analisou o volume destinado ao $7^{\circ}$ ano do ensino fundamental das duas coleções mais vendidas no Brasil, o que totalizava mais de $50 \%$ do total de livros adquiridos no PNLD 2011. Com essa escolha, seria possível inferir sobre a proposta de contextualização apresentada a mais da metade dos alunos de escolas públicas brasileiras do $7^{\circ}$ ano. É importante observar que o objeto de estudo de Souza não foi um conceito matemático, o que, de certa forma, demandou cuidados especiais no uso da TAD.

Gonçalves (2016, p.6) buscou "compreender distanciamentos e aproximações entre a construção dos números inteiros e propostas de ensino das operações de adição e subtração desse conjunto em um livro didático do $7^{\circ}$ ano do ensino fundamental. " Apesar de o objeto matemático números relativos ocupar, em geral, apenas um capítulo do livro, foi preciso delimitar a análise ao volume 7 da coleção mais vendida, uma vez que, devido ao objetivo da pesquisa foi realizado um estudo sobre a construção dos inteiros relativos.

Ramalho (2016, p.28) teve como objetivo de pesquisa "caracterizar o ensino de trigonometria em livros didáticos destinados ao $9^{\circ}$ ano do ensino fundamental, aprovados pelo PNLD do ano de 2014". Nesse ano foram aprovadas 10 coleções, porém, devido ao tempo disponível para a realização da pesquisa, não seria possível analisar todas elas, mesmo o conteúdo de análise não sendo tão extenso. Assim, foram escolhidas as 4 coleções mais adotadas pelas escolas públicas, o que totalizou mais de $70 \%$ de todas as coleções adquiridas pelo Fundo Nacional de Desenvolvimento da Educação (FNDE).

Freitas (2015) tinha como objetivo caracterizar a proposta de ensino de volume de sólidos geométricos em livros didáticos destinados ao ensino médio. Para tanto, e pelos mesmos motivos de Ramalho, Freitas analisou as 4 coleções mais adotadas e aprovadas no PNLD 2012.

\section{Separando Parte Curso e Parte Atividades propostas para análise}

Para a análise dividimos o texto do LD em duas partes: Curso e Atividades propostas. A Parte Curso compreende a explanação de definiçõos, propriedades, 
resultados e exercícios resolvidos. Nessa Parte os autores do livro didático trazem, mesmo que implicitamente, o que consideram que os alunos daquele nível de escolaridade devem aprender e é nessa Parte que os alunos buscam pistas para resolver o que lhes é pedido. A análise da Parte Curso permite identificar alguns tipos de tarefas que parecem importantes naquela instituição, neste caso o LD. Ilustro com um excerto extraído da pesquisa de Nogueira (2008).

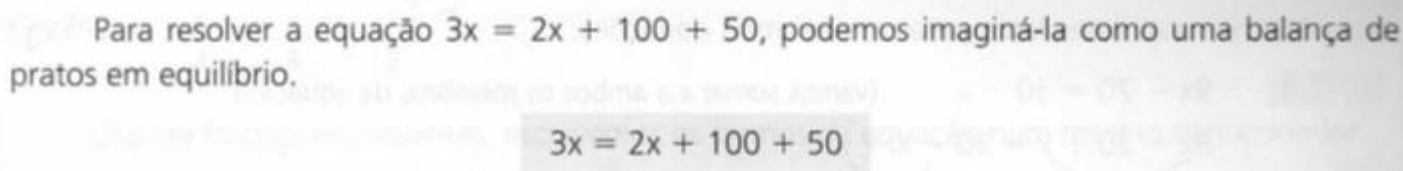

Na balança
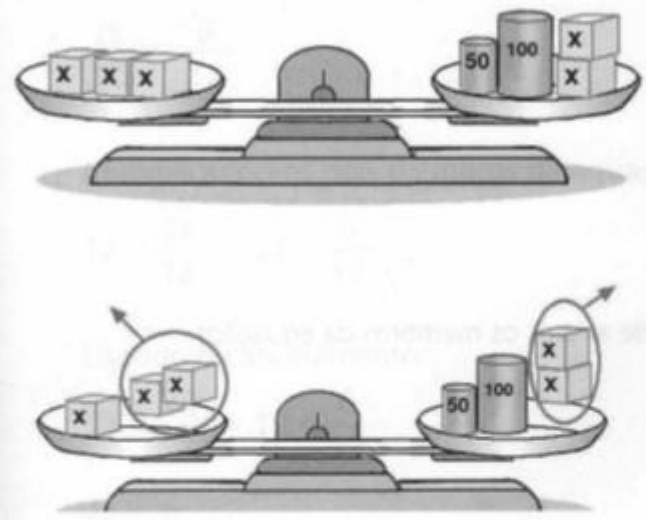

Retiramos a mesma massa dos dois pratos: o equilibrio se mantém.

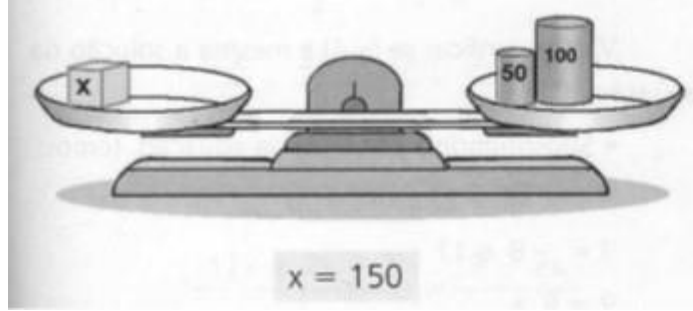

Na equação

$$
\begin{aligned}
& 3 x=2 x+100+50 \\
& 3 x=2 x+150 \\
& 3 x-2 x=2 x+150-2 x
\end{aligned}
$$$$
x=150
$$
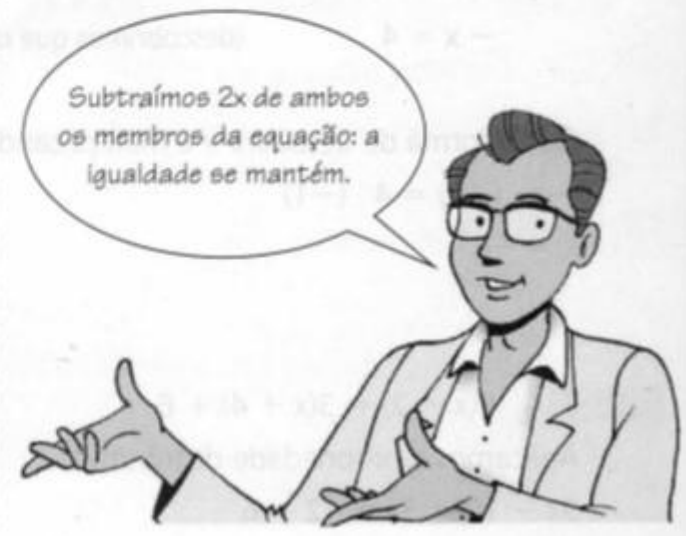

Figura 1: Identificação de tarefa e técnica na Parte Curso

Fonte: Nogueira $(2008, \mathrm{p} .85)$

O autor do livro didático apresenta uma tarefa modelada como pertencente ao tipo Resolver uma equação do $1^{o}$ grau do tipo $a x+b=c x+d$ e para sua resolução faz analogia com uma balança de pratos. Do lado esquerdo da figura 1 representa-se a equação, por meio de pesos, na balança e, em seguida, pesos de mesma massa são retirados de cada prato, o que permitirá que a balança permaneça em equilíbrio. Do lado direito da figura representa-se algebricamente a equação e os mesmos passos realizados 
com a balança, à esquerda, são realizados na equação à direita. A técnica proposta para sua resolução é a que Nogueira (2008, p.63) denominou algébrica ( $\tau 2)$ :

Esta técnica respeita a propriedade das igualdades entre dois números, fazendo a analogia entre a equação e uma balança em equilíbrio, onde se pode realizar operações matemáticas nos dois membros simultaneamente, desde que se mantenha o equilíbrio inicial, para que se encontre equações equivalentes, cada vez mais simples, visando encontrar o valor desconhecido. Nesta, partimos do que não conhecemos para encontrar seu valor.

A técnica de resolução proposta é justificada pela balança que desempenha, nesse caso, papel de tecnologia ${ }^{13}$.

A análise da Parte Curso permite, portanto, a produção de quartetos praxeológicos que serão testados e, talvez, modificados ao estudar a Parte Atividades Propostas.

Essa primeira análise permite identificar o conjunto de tarefas a serem reagrupadas em Tipos de tarefas. Como ressalta Artaud (2005) a noção de Tipo de tarefas tem como principal função permitir o agrupamento de tarefas julgadas suficientemente próximas. Essa modelagem depende, ao mesmo tempo, da realidade modelada, da instituição em que se emprega o trabalho conduzido e, claro, do pesquisador que faz a análise.

Uma vez realizada a análise da Parte Curso, passamos às Atividades Propostas. Nesse momento buscamos analisar cada atividade identificando qual é a tarefa do aluno e qual é a técnica que se espera que ele utilize para a resolução da tarefa, tendo como apoio a(s) praxeologia(s) anteriormente identificada(s). Uma pergunta recorrente, e totalmente pertinente, é "como saber que essa é a técnica que o autor gostaria que fosse usada?" Para realizar tal inferência baseamo-nos no que está presente no Manual do Professor e, principalmente, no que foi trabalhado na Parte Curso. Por meio dessa análise procuramos elementos que permitam inferir sobre como os autores do LD desejariam que seus usuários resolvessem as atividades. Tal inferência apoia-se no conceito de Contrato Didático (Brousseau, 1986): o aluno busca, na ação do professor ou no livro didático, encontrar algum sinal do que é esperado que ele faça.

Quando o livro analisado possui Manual do Professor $^{14}$ (MP) seu estudo é um aliado importante do pesquisador uma vez que, em geral, apresenta e justifica as escolhas realizadas pelos autores, além de algumas resoluções ou comentários sobre

\footnotetext{
${ }^{13}$ Nesse momento não vamos discutir a pertinência de usar a balança de dois pratos nesse tipo de situação. A adequação (ou não) de tal uso deve ser feita pelo pesquisador quando da análise dos dados produzidos.

14 Todas as coleções de livros didáticos presentes em escolas públicas brasileiras contêm o Manual do Professor, pois essa é uma das exigências para aprovação no Programa Nacional do Livro Didático (PNLD), que avalia obras didáticas a serem adquiridas por escolas públicas. Assim, no Brasil essa parte do LD fornece mais uma fonte rica de análise, o que nem sempre ocorre em outros países.
} 
atividades propostas. Nem sempre há coerência absoluta com o que é anunciado no MP e o que é praticado no livro do aluno, como já observado em análises realizadas por mim e colegas, no âmbito do Programa Nacional do Livro Didático (PNLD). Até mesmo tal conclusão é importante para compreender intenções dos autores.

\section{Elaboração do quarteto praxeológico matemático}

O início da análise é sempre um momento difícil, porém essa não é prerrogativa apenas de quem utiliza o modelo metodológico explicitado neste texto. Esse é o momento em que o pesquisador vai se colocar diante dos dados produzidos e realizar uma leitura utilizando para isso as suas lentes. São elas que nos dizem o que olhar e como olhar. É nesse momento que todo o estudo já realizado, incluindo levantamento de pesquisas (as vezes chamado de estado da arte) e o próprio estudo da(s) teoria(s) fará a diferença.

Para a modelagem da OM é realizada uma leitura, linha por linha, da Parte Curso, sem esquecer os boxes tão comuns em LD brasileiros e que podem dar a impressão de trazerem informação extra, talvez não necessário. Pode ocorrer, como já verificamos, que tais boxes apresentem algumas justificativas para as técnicas apresentadas. Assim, a leitura para a elaboração do quarteto praxeológico matemático deve ser feita levando em consideração todos os elementos de cada página do livro, entretanto nem todos serão considerados na modelagem realizada. Na Parte Curso, uma tarefa nem sempre é apresentada explicitamente; muitas vezes o estudo de um determinado conteúdo é proposto por meio de atividade resolvida, como, "Vamos estudar como calcular a altura de um prédio" (figura 2).

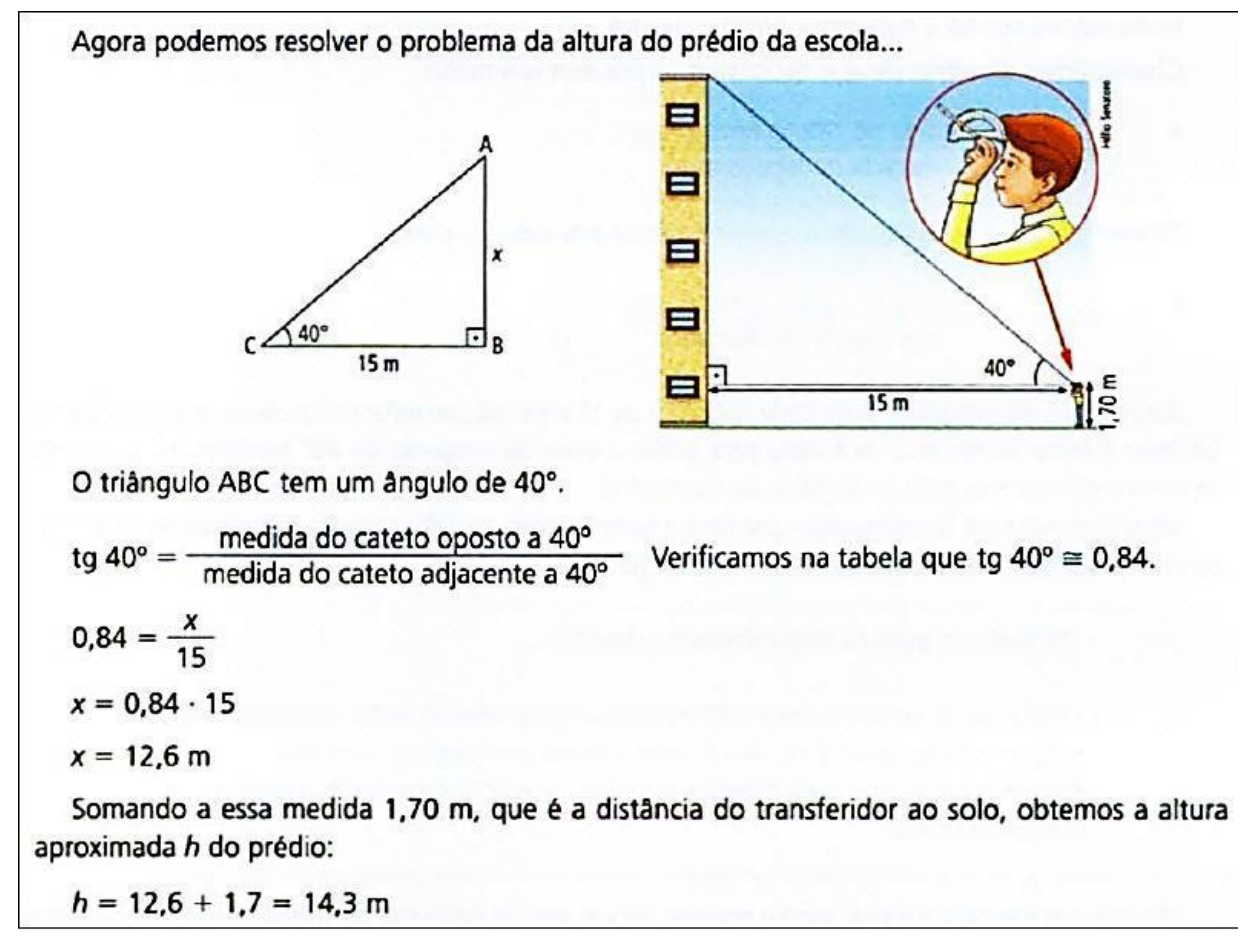


Figura 2: exemplo de apresentação do bloco prático-técnico

Fonte: Ramalho (2016, p.47)

O problema a ser resolvido foi modelado por meio de um triângulo retângulo e a tarefa passou a ser Calcular a medida do cateto oposto a um ângulo, dadas as medidas da hipotenusa e a desse ângulo ${ }^{15} \mathrm{e}$, para sua solução devem ser mobilizadas duas técnicas: (i) Substituir o valor tangente de um ângulo e a medida do cateto adjacente (oposto) a esse ângulo na razão que define tangente e resolver equação do $1^{o}$ grau para encontrar a medida do cateto oposto (adjacente) e (ii) Somar a medida encontrada a uma medida dada (ou a outra medida calculada) para encontrar a medida total pedida. É importante observar que técnicas também são tarefas. Além disso, o que é tarefa em um momento pode ser técnica posteriormente. Por exemplo, fatorar uma expressão algébrica pode ser uma tarefa ou pode compor uma técnica para resolver uma equação algébrica.

Algumas vezes iniciamos a análise com o apoio de uma praxeologia a priori ${ }^{16}$ que é modelada com a ajuda de estudos anteriores. Esse foi o caso da pesquisa de Kaspary (2014) sobre as operações de adição e subtração de números naturais, que fazem parte do Campo Aditivo (Vergnaud, 1990). No estudo desse campo, esse autor identificou 6 (seis) tipos de situações: composição de duas ou mais medidas; transformação sobre uma medida para resultar em outra medida; relação de comparação entre duas medidas; composição de duas ou mais transformações; transformação de um estado relativo; composição e dois ou mais estados relativos. Com o apoio nesse estudo e no de outros pesquisadores, Kaspary modelou 15 tipos de tarefas a priori, tendo em vista que:

Esses tipos de tarefas caracterizam aquelas do tipo contextualizadas que compreendem as diferentes ideias próprias do campo aditivo, das quais os alunos podem - ou deveriam - se deparar ao estudar o campo aditivo. A presença ou ausência desses tipos de tarefas nos livros didáticos nos possibilita entender parte do ensino proposto. (Kaspary, 2014, p.51)

Assim, Kaspary tinha uma grade para a análise. É importante ressaltar que não se trata de classificar as tarefas encontradas nos livros em um dos tipos de tarefas estabelecidos a priori, mas sim de ter uma base de apoio e um quadro para a análise. Para ilustrar cito um tipo de tarefas muito presente na coleção analisada e que não faz parte da praxeologia a priori modelada pela autora: "Calcular a adição ou a subtração de duas ou mais medidas". Um exemplo de uma tarefa desse tipo é "Calcular 17+12". De fato, não se trata de uma situação que envolve qualquer tipo de contexto, mesmo que de modo superficial. Vergnaud (1990) não se interessou a esse tipo de situação, mas

\footnotetext{
15 Para não perder de vista tentativas de contextualização presentes na coleção, foram criados dois grupos de tarefa, G1: Resolver uma situação que envolve triângulos retângulos em um contexto extraescolar e G2: Resolver uma situação que envolve triângulos retângulos em um contexto matemático.

${ }^{16}$ A inspiração para a designação "a priori” vem da teoria das situações didáticas (Brousseau, 1986) e carrega, em si, a mesma ideia da análise a priori.
} 
àquelas que dão significado ao conceito, que são, de certa forma, contextualizadas. Porém, estas não são as únicas trabalhadas no ensino

\section{Sobre a modelagem de tipos de tarefas}

Não existe uma maneira única de modelar o(s) quarteto(s) praxeológico(s). Isso varia de acordo com o objetivo da pesquisa, do objeto matemático em estudo e da instituição na qual tal estudo é realizado.

Na pesquisa de Freitas (2015), que versava sobre a proposta de ensino de volume em livros didáticos do ensino médio, os tipos de tarefas foram subdivididos em subtipos de tarefas para uma compreensão mais aprofundada e detalhada da proposta de ensino. Tomemos como exemplo o tipo de tarefa "T1: Calcular o volume de um sólido", encontrado 438 vezes nas 4 coleções analisadas pelo pesquisador. Com esses dados em mãos Freitas percebeu que a maioria das tarefas faziam referência a sólidos conhecidos, como pirâmides e prismas regulares. Entretanto, haviam também tarefas destinadas ao cálculo de volumes de sólidos irregulares. Para uma análise mais fidedigna da proposta de ensino de volume, o tipo de tarefa T1 foi dividida em dois subtipos: T1 1 : Calcular o volume de um sólido conhecido e $\mathrm{T}_{2}$ : Calcular o volume de um sólido irregular. Foram encontradas 408 tarefas do primeiro subtipo e 30 do segundo, o que revela escolhas do autor e que não seria possível perceber se a modelagem fosse feita considerando T1 e T2 como um único tipo de tarefa ou considerando-as de modo separado, mas sem realizar a quantidade de tarefas em cada dos dois tipos.

É importante ressaltar que a quantidade total de tarefas encontradas em um livro não coincide com o total de atividades propostas. Com efeito, é comum uma atividade proposta ser associada a mais de um tipo de tarefa, como no exemplo a seguir, retirado da pesquisa de Almeida (2015), cujo objeto matemático de estudo foi polígonos e figuras espaciais formadas por polígonos.

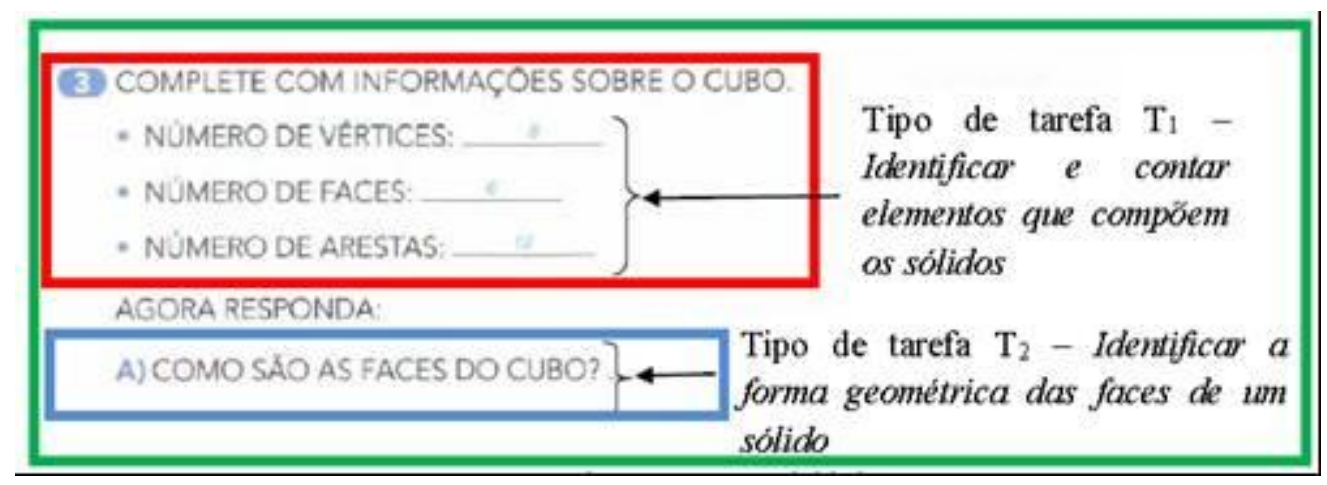

Figura 3: Exemplo de atividade com duas tarefas de tipos diferentes de tarefas Fonte: Almeida (2015, p.45)

Nem sempre uma técnica é algoritmizável. Por exemplo, para resolver a tarefa do tipo T1 da atividade proposta, é preciso contar a quantidade de vértices, de faces e de arestas e para fazer isso, nos anos iniciais, é preciso manipular o sólido, identificar os 
elementos e fazer a contagem sem deixar nenhum elemento de fora e sem contar duas vezes um mesmo elemento ${ }^{17}$. Percebe-se assim que nem sempre uma técnica se parece com o que temos o hábito de chamar de técnica matemática. Essa técnica pode ser considerada autotecnológica (Chevallard, 1998, p.42), pois "existe uma naturalidade institucionalmente aceita em praticar tal técnica, tornando sua justificativa desnecessária, por essa ser a "boa maneira" de fazer". Nesse exemplo a justificativa está embutida na técnica: se contar todos os vértices e sem repetição, "é claro" que o resultado será a quantidade de vértices do cubo.

Outra consideração que vale a pena ser feita diz respeito ao fato de que, de acordo com o objetivo da análise, pode ser preciso distinguir técnicas principais de técnicas secundárias. Esse foi o caso da pesquisa de Nogueira (2008) sobre a introdução da álgebra em livros didáticos do ensino fundamental.

Para o estudo das técnicas relativas à resolução de equações do $1^{\circ}$ Grau procedemos da seguinte forma: analisamos as atividades resolvidas e separamos as técnicas em duas categorias, as principais e as auxiliares. As principais [...] estão diretamente ligadas à resolução de equações propriamente dita; as auxiliares vêm ao encontro das técnicas principais, dando subsídios para resolver por completo a atividade, atendendo a todas as solicitações do enunciado. (Nogueira, 2008, p.63)

A autora modelou três técnicas principais - aritmética ou inversa $(\tau 1)$, algébrica $(\tau 2)$ e transposição $(\tau 3)$ - e 14 secundárias, dentre estas, cito "Aplicar a propriedade distributiva da multiplicação" e "Reduzir termos semelhantes". Para ilustrar trago um exemplo da dissertação de Nogueira (Figura 4):

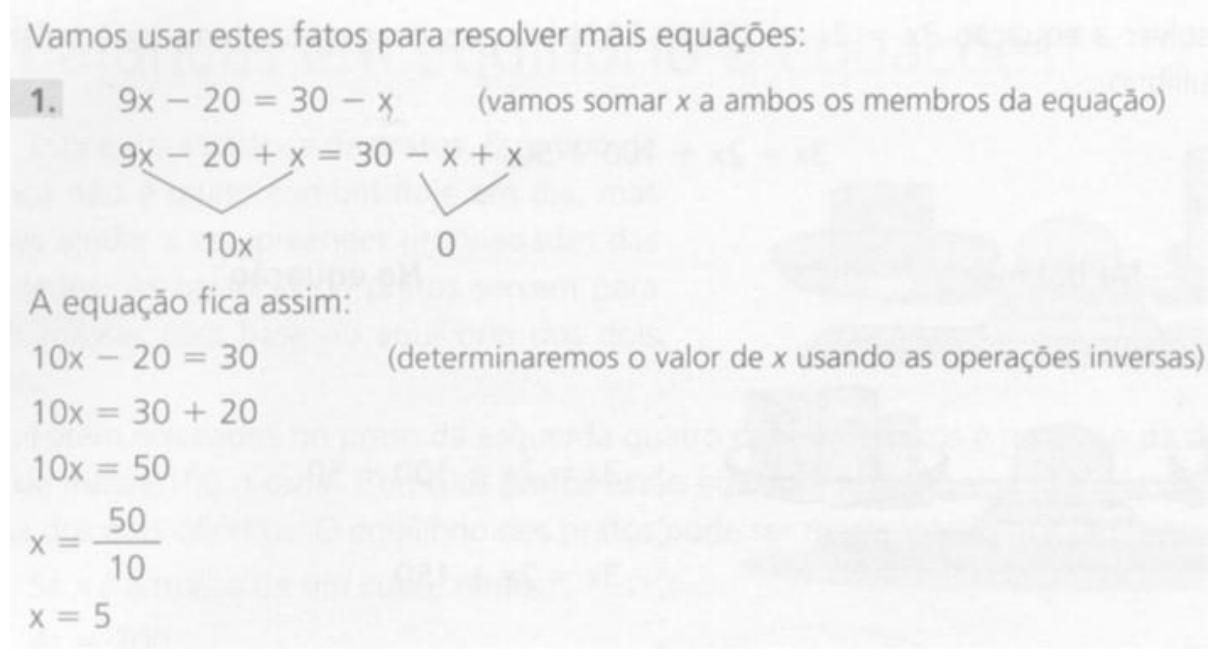

Figura 4: Identificação de técnicas secundárias

Fonte: Nogueira (2008, p.86)

A tarefa em desenvolvimento no $\mathrm{LD}$ refere-se à resolução de uma equação do $1^{\circ}$

\footnotetext{
${ }^{17}$ Esta é uma releitura do que é apresentado por Almeida, pois à época a modelagem foi um pouco diferente.
} 
grau que não está na forma $a x+b=c$. Na resolução apresentada inicialmente é feita a redução de termos semelhantes obtendo-se a equação em sua forma canônica e, então, é aplicada a técnica aritmética (ou das operações inversas). Assim, a redução de termos semelhantes é fundamental para a resolução da atividade, entretanto, para melhor compreender a proposta é essencial distinguir técnicas auxiliares ou secundárias das técnicas principais que constituem o objeto de estudo naquele momento. Assim, uma técnica principal em uma praxeologia pode se tornar secundária em outra praxeologia, como é o caso das técnicas de resolução de uma equação do primeiro grau: no $7^{\circ}$ ano elas são objeto de estudo enquanto que no ensino médio devem ser mobilizadas, entre outros, para resolver um problema de geometria analítica.

A análise dos tipos de tarefas e das técnicas que as resolvem teve dupla função na pesquisa de Souza (2014): identificar conteúdos algébricos presentes nos tipos de tarefas e nas técnicas envolvendo algum tipo de contextualização e identificar/classificar atividades contextualizadas propostas no LD, mesmo se de modo artificial.

As atividades 62 e 63 não pertencem ao campo algébrico, todavia a resolução, após sua modelagem, passa pela resolução de uma equação do $1^{\circ}$ grau, logo a tarefa é do campo geométrico e a técnica é do campo algébrico, o que faz dessa uma atividade contextualizada com a própria Matemática. (Souza 2014, p.63)

\section{Identificação do bloco tecnológico-teórico}

A identificação da tecnologia e da teoria tem constituído uma das grandes dificuldades do tipo de análise que temos realizado, especialmente em livros didáticos destinados aos anos iniciais do ensino fundamental. Nessa parte da análise é preciso lembrar a instituição na qual o objeto vive, mesmo porque o que pode ser aceito como justificativa em dado nível escolar pode não ser em outro nível. Freitas (2015) mostrou que o princípio de Cavalieri tem o papel, explícito, de justificar a fórmula para o cálculo do volume de um sólido qualquer. Já nos anos iniciais a situação não é a mesma. Para ilustrar trago um exemplo da pesquisa de Kaspary (2014) no qual a tarefa é "Calcular $278+145$ " e a técnica empregada é o algoritmo usual. A justificativa para a técnica pode ser percebida nos balões que representam as falas das crianças. Cada balão explica o procedimento realizado no quadro valor de lugar, da esquerda para a direita, até chegar à forma mais simplificada do algoritmo. Assim, a justificativa para a técnica "Uso do algoritmo usual" repousa no sistema de numeração decimal. 
DOI: http://dx.doi.org/10.20396/zet.v25i3.8648640
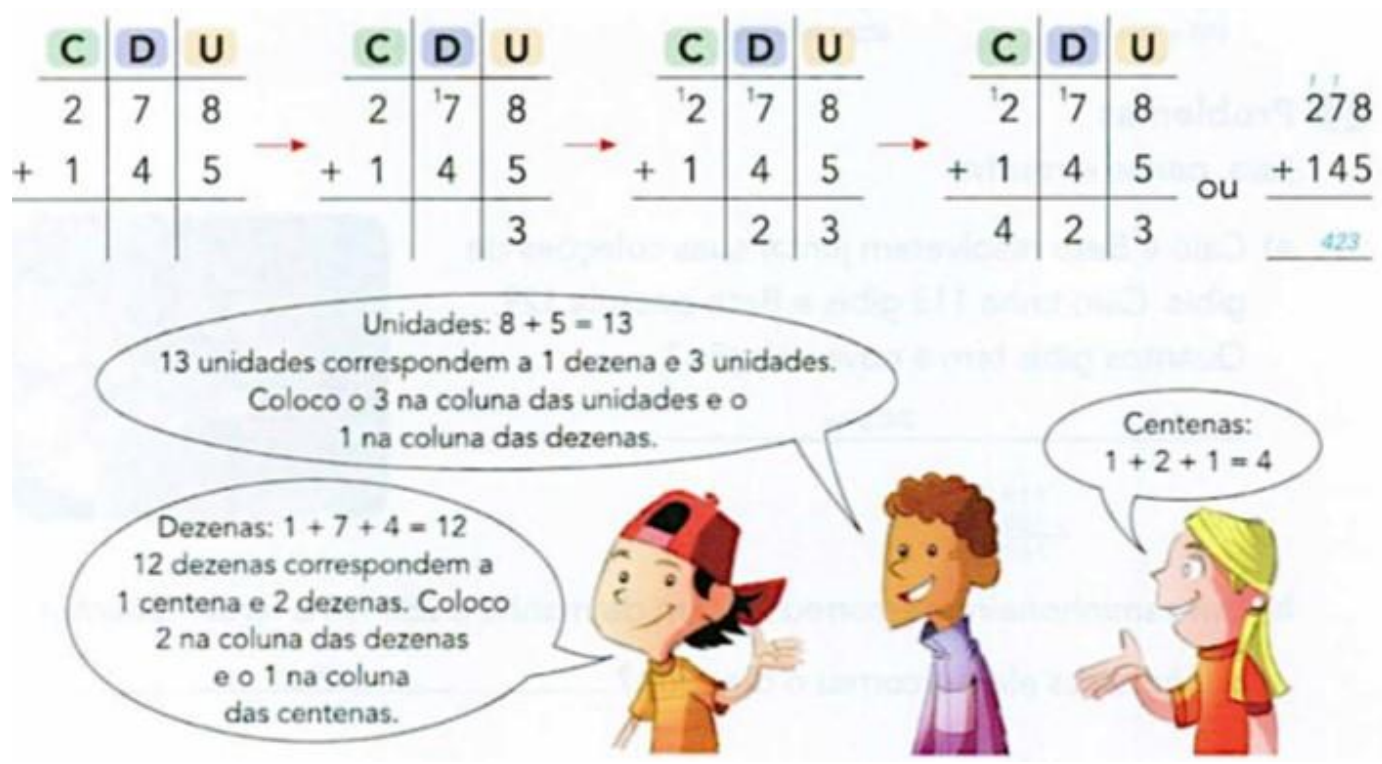

Figura 5: Apresentação de elementos tecnológicos Fonte: Kaspary (2014, p.107)

Em outros casos ainda, o bloco tecnológico-teórico, com caraterística mais matemática, está praticamente ausente do livro, como ocorre no estudo de números inteiros relativos nos anos finais do ensino fundamental. A propriedade "um número negativo multiplicado por outro número negativo resulta um número positivo" apresentada, em geral, no $7^{\circ}$ ano do ensino fundamental, nada tem de natural, logo, não é autotecnológica e, portanto, necessita de uma justificativa. Entretanto, qualquer justificativa de cunho matemático para esse resultado não pode viver nesse nível de escolaridade; não tem condições ecológicas para isso. Assim, as justificativas para esse e outros resultados relacionados a números inteiros relativos apoiam-se em artifícios didáticos como temperaturas, nível do mar, reta e outros, como mostrou Gonçalves (2016). Por artifícios didáticos designo escolhas realizadas por autores de livros com o objetivo de "facilitar" o entendimento dos alunos especialmente quando justificativas matemáticas são inacessíveis, como ocorre com os números inteiros relativos.

\section{Identificação de ostensivos}

Como dito anteriormente, o estudo de ostensivos e não-ostensivos é essencial para a compreensão da atividade matemática. Os ostensivos utilizados no enunciado de uma tarefa ou na técnica mobilizada para resolver essa tarefa definem, de certa forma, a atividade matemática. Os ostensivos mudam em função das condições e restrições de um objeto em uma determinada instituição. Assim, ostensivos com "maior materialidade", como desenhos de brinquedos, utilizados no primeiro ano da escola básica vão, aos poucos, sendo substituídos por outros mais compactos (abstratos, de certa forma), como risquinhos e bolinhas que, por sua vez, também serão abandonados posteriormente, como mostrou Kaspary (2014, p. 136): “Avaliamos as técnicas e percebemos que algumas delas deixavam de ser utilizadas devido ao fato de os 
ostensivos nelas empregados não propiciarem o trabalho com números maiores que 19, por exemplo". Na pesquisa de Ramalho (2016), sobre a trigonometria no $9^{\circ}$ ano, foi possível perceber o uso de ostensivos como tentativa de dar significado à trigonometria. Por exemplo, um problema de aplicação direta de uma relação trigonométrica no triângulo retângulo é, frequentemente, apresentado por meio de um desenho (ostensivo) no qual um dos lados do triângulo é uma parte de uma árvore, ou a trajetória (hipotética) de um avião. A identificação e análise do uso de tais ostensivos é fundamental para a compreensão das praxeologias propostas, entretanto não discutirei mais esse item devido ao limite de espaço de um artigo ${ }^{18}$.

\section{Elaboração da praxeologia didática}

A organização didática, resposta à questão "Como ensinar esse conteúdo?”, pode ser modelada de dois modos não excludentes: via o quarteto praxeológico didático e via os momentos de estudos (Chevallard, 1992). Para ilustrar a primeira opção, não farei uso de pesquisas já realizadas, pois desconheço trabalhos concluídos que tenham feito essa opção. Entretanto, farei uma breve exposição de como tal trabalho pode ser realizado.

Se o professor acredita que a aprendizagem ocorre por meio de reforço e estímulo, então isso transparecerá em sua escolha sobre a forma como cumprirá a tarefa "ensinar um determinado conteúdo". O aluno será constantemente convidado a repetir procedimentos, provavelmente quase nunca será confrontado a situações que estimulem a autonomia, a elaboração de conjecturas e outros. Assim, o bloco prático-técnico é justificado por teorias que não consideram o aluno como sujeito ativo e corresponsável por sua aprendizagem. Entretanto, a opção pode ser outra, caso o professor tenha outros paradigmas de aprendizagem, que considerem, por exemplo, importante, que o aluno elabore conhecimento. Consequentemente, haverá uma tentativa de organizar o estudo de modo a favorecer esse comportamento por parte do aluno. Assim, um quarteto praxeológico didático será definido por um tipo de tarefa didática, resolvida por uma técnica didática (escolha para a apresentação do conteúdo), que é justificada pelas crenças (outros) sobre como o aluno aprende (ou como queremos que ele aprenda questão ideológica). Vamos supor que a tarefa do professor é ensinar as fórmulas para o cálculo de área de figuras poligonais. Para resolver essa tarefa ele pode propor atividades no geoplano que levem os alunos a conjecturarem as fórmulas, ao invés de enunciá-las prontas. Tal escolha pode ser justificada por um paradigma de aprendizagem no qual o sujeito seja ativo e o conhecimento não se transmite.

Outra forma de caracterizar as opções de abordagens para o estudo de objetos matemáticos é por meio da análise dos seis (06) momentos de estudo, classificados por

\footnotetext{
18 Ao leitor interessado convido a realizar, em particular, a leitura de Kaspary (2014) que contém um estudo mais detalhado dos ostensivos presentes no campo aditivo em uma coleção de livros didáticos dos anos iniciais.
} 
Chevallard (1998) em: primeiro encontro com a praxeologia; exploração de um tipo de tarefa e elaboração de uma técnica que resolve esse tipo de tarefa; constituição do entorno tecnológico-teórico; trabalho com a técnica, visando torná-la melhor, mais confiável; institucionalização dos saberes que deverão fazer parte do arsenal dos alunos daquele nível escolar; avaliação da praxeologia trabalhada. É importante ressaltar que esses momentos não ocorrem, necessariamente, nessa ordem: é a identificação e análise de como eles ocorrem que vai permitir melhor compreender o ensino praticado. Há privilégio de algum momento em relação aos demais? Caso exista, o que isso significa? Kaspary (2014, p. 46) afirma que "a conclusão de que o primeiro momento coincide, recorrentemente, com a institucionalização de saberes matemáticos, como teoremas e propriedades, alerta para um ensino mais teoricista". Tal observação vai ao encontro de uma das conclusões de Ramalho (2016, p.83):

[...] verificamos nos quatro livros a valorização da construção do entorno tecnológico-teórico de trigonometria no triângulo retângulo, bem como do trabalho com as técnicas de resolução. Desse modo, a ênfase nesses dois momentos didáticos (terceiro e quarto), demonstrou que tais livros conduzem o ensino de trigonometria por meio de uma organização didática clássica [...].

A identificação e análise dos momentos de estudo pode ser fundamental para compreender ou, ao menos, levantar hipóteses sobre a proposta de ensino de objetos não matemáticos, como foi o caso da pesquisa desenvolvida por Souza (2014) sobre a contextualização em álgebra em livros didáticos do ensino fundamental.

Por meio da Organização didática identificamos os momentos nos quais as contextualizações ocorriam e, assim, foi possível verificar também os momentos temporais, ou seja, se a contextualização era utilizada para apresentar um conceito, para a exposição de tarefas relacionadas a ele ou ainda para finalizar a abordagem de um conceito. (Souza, 2014, p. 95)

\section{Análise das praxeologias modeladas}

Uma vez obtidas as OM e as OD, é preciso interpretar as informações obtidas. Nogueira (2008) modelou a OM da parte Curso, da Parte Atividades Propostas e também a OD de cada coleção analisada, o que lhe forneceu um resultado de análise ( $\mathrm{Ri}$ ) de cada coleção. Em seguida, confrontou os três resultados (figura 6) para, então, responder sua questão de pesquisa. A figura 6 , a seguir, representa o desenho metodológico desenvolvido pela pesquisadora. 
DOI: http://dx.doi.org/10.20396/zet.v25i3.8648640

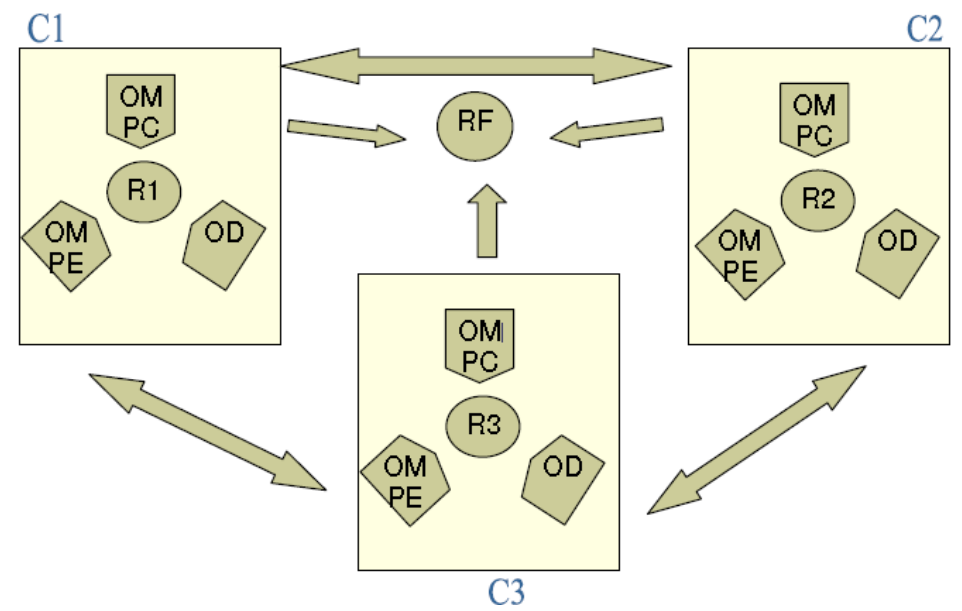

Figura 6: Esquema metodológico

Fonte: Nogueira (2008, p.55)

Para resolver equações do $1^{\mathrm{o}}$ grau foram modeladas três técnicas principais: aritmética $(\tau 1)$ que consiste em efetuar operações inversas às presentes na equação para obter o resultado; algébrica $(\tau 2)$ que consiste em efetuar operações algébricas justificadas pela analogia com a balança; transposição ( $\tau 3)$ que consiste na retórica da técnica algébrica, e que há supressão de passagens ${ }^{19}$. Entretanto, da confrontação dos dados a autora concluiu que a evolução das praxeologias não ocorre da mesma forma nas três obras analisadas. Na coleção $\mathrm{C} 1$ há uma evolução não equilibrada das praxeologias $(T, \tau 1) \rightarrow(T, \tau 2)$, pois há forte ênfase na primeira delas; além disso a praxeologia $(T, \tau 3)$ não é contemplada nessa coleção. $\mathrm{Na}$ coleção $\mathrm{C} 2$, as três praxeologias estão presentes, sendo que as duas primeiras recebem mais atenção e a terceira aparece timidamente em algumas poucas atividades. Já na coleção C3, a praxeologia $(T, \tau 1)$ é ausente, sendo enfatizada $(T, \tau 2)$ com o aparecimento de $(T, \tau 3)$ somente nas páginas finais do capítulo. A pesquisadora conclui que tanto $\mathrm{C} 1$ quanto $\mathrm{C} 2$ "contemplam, cada qual ao seu tempo, a passagem da aritmética para a álgebra, o que não ocorre com a coleção C3, que já inicia apresentando uma técnica especificamente algébrica" (Nogueira, 2008, p.96). Percebe-se assim, como a análise da evolução das praxeologias fornece elementos para melhor compreender as escolhas dos autores de livros didáticos.

Outro fator importante a ser considerado é a quantificação dos dados produzidos tanto no que se refere às OM quanto às OD. Kaspary (2014) produziu um gráfico a partir dos dados obtidos com a modelagem da OD (figura 7), ou seja, uma vez identificados os diversos momentos de estudo presentes ao longo de toda a coleção, esses foram analisados e codificados para gerar os pontos do gráfico. Assim fazendo, as escolhas metodológicas da coleção analisada puderam ser melhor evidenciadas.

\footnotetext{
${ }^{19}$ Essa técnica pode estar na origem de algumas dificuldades de alunos que são levados a repetir o bordão «passa para o outro lado, muda de sinal ».
} 


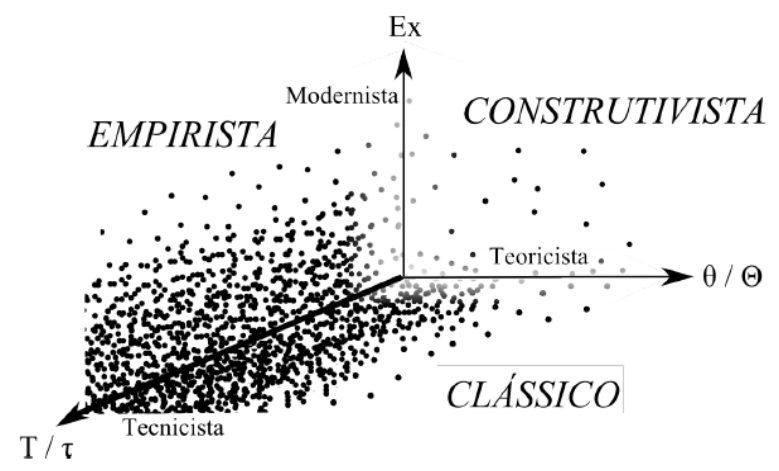

Figura 7: Organização didática da coleção analisada Fonte: Kaspary (2014, p.136)

Os pontos do gráfico representam os diversos momentos de estudo presentes ao longo de toda a coleção depois de analisados e codificados. A leitura desse gráfico permitiu colocar em evidência as escolhas metodológicas da coleção analisada, conforme afirma a autora:

Essa sistematização da organização didática proposta se pauta na ênfase dada aos elementos tecnológicos que visam uma melhor e mais consciente operacionalização das técnicas, bem como nas tentativas, mesmo que menos frequentes, de propor situações que levem o aluno a explorar técnicas de resolução, como em atividades do cálculo mental. (Kaspary, 2014, p.136)

Assim, a quantificação permitiu identificar, por um lado, a tendência pedagógica da obra e, por outro, o fato de que apesar de haver uma tendência predominante, a obra contempla, mesmo que em pouca quantidade, outras tendências.

Praxeologias vêm e vão...

A análise da evolução de praxeologias indica também que algumas praxeologias desaparecem ao longo do estudo o que coloca, ao pesquisador, a seguinte questão: qual a razão de ser de praxeologias que aparecem para desaparecer, muitas vezes, logo em seguida? Para compreender a atividade matemática de um sujeito em uma determinada instituição essa é uma questão necessária de ser investigada. As pesquisas realizadas em nosso grupo já nos permitiram identificar ao menos duas razões: uma praxeologia pode ser apresentada tendo como objetivo principal justificar/apresentar outra praxeologia, a que se deseja ver institucionalizada e que vai permanecer na instituição. É o caso da técnica aritmética, no estudo das equações de grau 1, como mostrou Nogueira (2008): esta técnica tem como principal função de justificar a técnica algébrica que, em seguida, justifica a técnica da transposição. Outro motivo para o aparecimento esporádico de algumas praxeologias parece ser em função das demandas da noosfera ${ }^{20}$, como indicam as pesquisas de Ramalho (2016) e Souza (2014). Vejamos, primeiramente, um exemplo

20 Noosfera é um termo designado por Chevallard para indicar a instância, no processo de transposição didática, que vai influenciar/decidir os saberes a serem ensinados. 
extraído da pesquisa de Ramalho, que ilustra o desejo de autores de atenderem a demanda da noosfera, expressa em documentos oficiais: o ensino da trigonometria no ensino fundamental tem como um de seus motes a aplicação em contextos práticos.

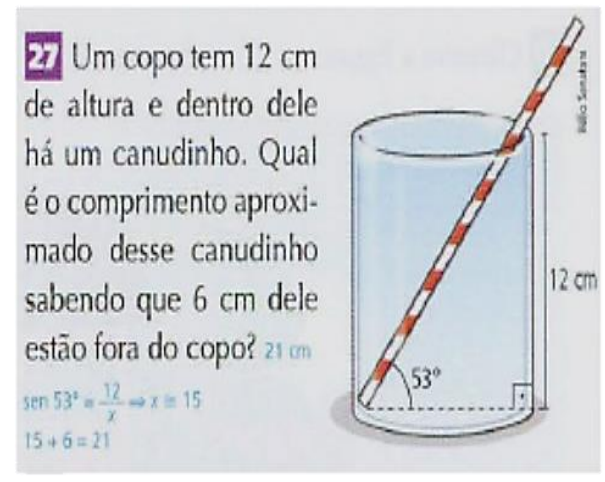

Figura 8: exemplo de atividade para atender a noosfera Fonte: Ramalho (2016, p.82)

Calcular a medida de um canudinho usando trigonometria consiste, de fato, um contexto prático para a trigonometria? Qual o significado dessa atividade? A análise dessa e de outras atividades semelhantes que permitiu a Ramalho inferir sobre a influência da noosfera na elaboração do LD. Tal influência também foi evidenciada por Souza (2014, p.69):

O manual [...] apresenta 435 tarefas das quais 153 são contextualizadas, o que expressa certo interesse em propor situações contextualizadas. Dentre essas, a maioria são artificiais ou são pseudo-contextualizações, como foi possível observar pela análise realizada. Raramente identificamos situações que propunham contextualizações articuladas; em geral os enunciados são propostos com o intuito de chamar a atenção para a atividade ou ainda para que haja um texto e não apenas uma situação do tipo "Resolva". Com relação às associações com outras áreas do conhecimento, poucas foram as situações referentes a essa categoria. Em todo o manual apenas duas situações foram identificadas, dessas nenhuma trata uma contextualização articulada. Do mesmo modo, as contextualizações históricas dificilmente aparecem no manual e quando ocorrem é a título de curiosidade. (Souza, 2014, p.69)

A análise articulada da OM e da OD, juntamente com a quantificação das praxeologias modeladas, permitiu a Souza (2014) caracterizar a contextualização em álgebra em LD. A quantidade de tarefas classificadas como contextualizadas evidencia preocupação dos autores em atender a demanda da noosfera. Entretanto, tais situações pouco favorecem que o estudante perceba como a álgebra pode ajudar a resolver problemas de outros campos da Matemática.

\section{Conclusão}

Neste texto busquei apresentar algumas potencialidades da teoria antropológica do didático, especialmente para a análise de livros didáticos, ao mesmo tempo em que 
apresento à comunidade de educadores (matemáticos) um caminho metodológico para realizar tal análise. É importante ressaltar que esse caminho é dinâmico e está continuamente em processo de estudo. Assim sendo, não há uma conclusão para esse artigo, como há em artigos de outra natureza. Normalmente a ideia seria de "avaliar" o modelo proposto, mas creio que isso foi feito ao longo do texto, por meio dos exemplos apresentados e que sustentaram a elaboração da proposta que apresento. Assim, um próximo passo - que pode ser visto como de avaliação do modelo proposto - é ampliar o espectro de materiais a serem analisados na perspectiva proposta. De certa forma considero que estamos - meus orientandos e eu - realizando tal avaliação. Com efeito, apesar de a grande maioria das pesquisas nacionais e internacionais realizadas sob a ótica da TAD investigar a atividade matemática quando o que está em foco é o estudo de um objeto matemático, temos utilizado essa ferramenta teórica e metodológica também quando o foco da investigação não é um objeto matemático, como foi o caso da pesquisa de Souza (2014) sobre contextualização em álgebra. Nessa mesma perspectiva está em desenvolvimento a pesquisa de mestrado de Jéssica Serra Corrêa da Costa sobre o cálculo mental em livros didáticos destinados aos anos iniciais.

Por fim, saliento que neste artigo foi discutida apenas uma das possibilidades de uso da TAD. Diversas investigações têm sido realizadas usando outras ferramentas teóricas não exploradas nesse texto ou aprofundando alguns aspectos aqui discutidos inclusive no DDMat - Grupo de estudos em didática da matemática ${ }^{21}$, como é o caso de modelos epistemológicos de referência. Mas, esse é outro assunto, ou, como diriam nossos parceiros franceses, Il y a du pain sur la planche.

\section{Referências}

Almeida, M. S. M. (2015). A Articulação entre o Ensino de Polígonos e Poliedros em uma Coleção de Livros Didáticos dos Anos Iniciais do Ensino Fundamental. Dissertação de Mestrado em Educação Matemática. Campo Grande: Universidade Federal de Mato Grosso do Sul.

Artaud, M. (2005). La TAD comme théorie pour la formation des professeurs. Actes $d u$ $1^{\circ}$ congrès international sur la Théorie Anthropologique du Didactique, Jaen, Espagne.

Bittar, M. (1998). Les vecteurs dans l'enseignement secondaire. Aspects outil et objet dans les manuels. Etude de difficultés d'élèves dans deux environnements: papier crayon et Cabri-géomètre II. Tese de doutorado em Didática da Matemática. Grenoble: Universidade Joseph Fourier.

Bosch, M., Chevallard, Y. (1999) La sensibilité de l'activité mathématique aux ostensifs. Objet d'estude et problematique. Recherches en Didactique des Mathématiques, 19(1), 77-124.

\footnotetext{
${ }^{21}$ grupoddmat.pro.br
} 
Brosseau, G. (1986). Fondements et méthodes de la Didactique des Mathématiques. Recherches en Didactique des Mathématiques, 7(2), 33-115.

Chaachoua, H., Comiti C. (2010) L'analyse du rôle des manuels dans l'approche anthropologique, ACTES CITAD2, p. 771-789

Chevallard, Y. (1992). Concepts fondamentaux de la didactique: perspectives apportées par une approche anthropologique. Recherches en Didactique des Mathématiques, 12(1), 73-112.

Chevallard, Y. (1998) Analyse des pratiques enseignantes et didactique des mathématiques: L'approche anthropologique. Recherches en Didactique des Mathématiques, 19(2), 221-266.

Chevallard, Y. (1991). La transposition didactique. Grenoble: La pensée Sauvage.

Freitas, M. V. C. (2015). Um estudo sobre volume de sólidos geométricos em uma coleção de livros didáticos do Ensino Médio. Dissertação de Mestrado em Educação Matemática. Campo Grande: Universidade Federal do Mato Grosso do Sul.

Gascón, J. (2003) La necessidade de utilizar modelos em didáctica de la matemáticas. Educação Matemática e Pesquisa, São Paulo, v. 5, n. 2, pp. 11 - 37.

Gonçalves, K. R. (2016). A teoria antropológica do didático como ferramenta para o estudo de transposições didáticas: o caso das operações de adição e subtração dos números inteiros no $7^{\circ}$ ano do ensino fundamental. Dissertação de Mestrado em Educação Matemática. Campo Grande: Universidade Federal de Mato Grosso do Sul.

Kaspary, D. (2014). Uma análise praxeológica das operações de adição e subtração de números naturais em uma coleção de livros didáticos dos anos iniciais do Ensino Fundamental. Dissertação de Mestrado em Educação Matemática. Campo Grande: Universidade Federal do Mato Grosso do Sul.

Nogueira. R. C. S. (2008). A Álgebra nos Livros Didáticos do Ensino Fundamental: uma análise praxeológica. Dissertação de Mestrado em Educação. Campo Grande: Universidade Federal de Mato Grosso do Sul.

Oliveira, A. B. de. (2010). Prática pedagógica e conhecimentos específicos: um estudo com um professor de matemática em início de docência. Dissertação de Mestrado em Educação Matemática. Universidade Federal de Mato Grosso do Sul

Ramalho, L. V. (2016). Trigonometria em livros didáticos do $9^{\circ}$ do ensino fundamental. Dissertação de Mestrado em Educação Matemática. Campo Grande: Universidade Federal de Mato Grosso do Sul.

Shulman, L. (2001) Knowledge and teaching: Foundations of the new reform. Harvard Educational Review. Tradução: Alberto Ide. 57(1), 163-196.

Souza, N. F. (2014). Contextualização no ensino da Álgebra: Análise de livros didáticos do $7^{\circ}$ ano. Dissertação de Mestrado em Educação Matemática. Campo Grande: Universidade Federal do Mato Grosso do Sul. 
DOI: http://dx.doi.org/10.20396/zet.v25i3.8648640

Vergnaud, G. (1990). La théorie de champs conceptuels. Recherches en Didactique de Mathématiques, 10(2.3), 133-170. 